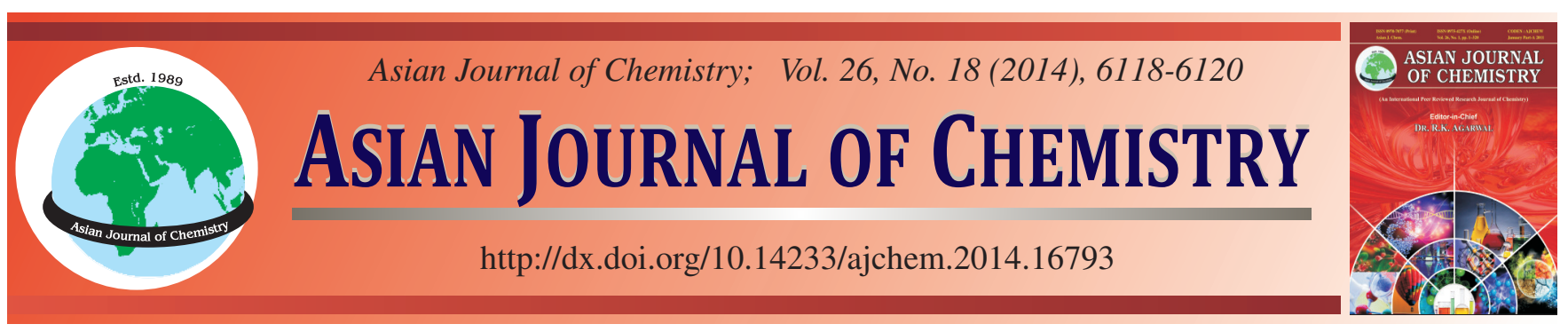

\title{
A Chemical Research on Three Red Algae Gracilaria bursa-pastoris, Phyllophora crispa and Laurencia obtusa var. pyramidata
}

\author{
Kasim C. Güven ${ }^{1, *}$, Burak Coban ${ }^{2}$ and Huseyin ERdugan ${ }^{3}$
}

${ }^{1}$ Turkish Marine Research Foundation (TUDAV), 34820 Beykoz, Istanbul, Turkey

${ }^{2}$ Chemistry Department, Faculty of Science and Letters, Bulent Ecevit University, 67100 Zonguldak, Turkey

${ }^{3}$ Department of Biology, Faculty of Science, 18 Mart University, Çanakkale, Turkey

*Corresponding author: E-mail: kcguven@yahoo.com.tr

Received: 30 November 2013;

Accepted: 2 April 2014;

Published online: 1 September 2014;

AJC-15865

\begin{abstract}
In this paper, the exogenic and endogenic compounds in three red algae Gracilaria bursa-pastoris, Phyllophora crispa and Laurencia obtusa var. pyramidata were reported. Exogenic compounds detected are oil components and other pollutants such as, saturated and unsaturated aliphatic, cyclic and aromatic hydrocarbons, BHT, nonyl phenol and halogenated compounds as hexachloroethane and 4-chlorophenol. Endogenic compounds were fatty acids and its esters, eicosane, squalene, phytol. The algae can be used for monitoring of the sea pollution.

Keywords: Gracilaria bursa-pastoris, Phyllophora crispa and Laurencia obtusa var. pyramidata, Exogenic, Endogenic.
\end{abstract}

\section{INTRODUCTION}

The algae contain many compounds which were biosynthesized (biogenic, autochthonous) or taken from the sea pollutants (exogenic, anthropogenous). Biogenic compounds as halogenated compounds, sulfated and nonsulfated polysaccharides are specific for algae. Marine algae also absorb many sea pollutants such as metals ${ }^{1-2}$, radionuclides ${ }^{3}$ and numerous organics including hydrocarbons. These exogenic compounds have been monitored in terms of marine pollution. On the other hand, the origin of some hydrocarbons in algae still remains unexplained. The main problem of chemistry of algae is to decide whether these hydrocarbons found in algae are biogenic or exogenic, for example aliphatic petroleum hydrocarbons are also synthesized by algae 4 and also taken from the sea ${ }^{5-6}$. This problem can be solved by showing the difference in contents of the algae collected from various polluted and unpolluted areas ${ }^{7-9}$ but it is difficult to decide for an area which is polluted or unpolluted because today the oil contamination was demonstrated for all sea environments. Oil pollution of algae was shown by various authors ${ }^{4-20}$. Recently 69 aliphatic and 55 aromatic petroleum hydrocarbons were identified from the algae collected from Turkish coasts ${ }^{6}$.

Biogenic compounds detected in Laurencia sp. are: squalene $^{13}$ and cytotoxic squalene derivatives in L. obtusa ${ }^{21}$, phytol in $L$. papillosa ${ }^{22}$, L. tristich ${ }^{23}$, tetradecanoic acid in $L$. papillos $^{24}$, hexadecanoic acid in L. nipponica ${ }^{25}$, octadecanoic acid in L. pinnatifida ${ }^{26}$, fatty acids in Gracilaria bursapastoris $^{27}$, Gracilaria verrucosa and Phyllofora nervosa ${ }^{27}$. Gallaxolide ${ }^{\circledR}$ pollution was found in L. pyramidalis ${ }^{9}$.
In this paper, exogenic and endogenic compounds identified in three red algae were reported.

\section{EXPERIMENTAL}

The algae collected were Gracilaria bursa-pastoris (S.G. Gmelin) from Sogandere (Dardanelles) in June 2007; Phyllophora crispa (Hudson) P.S. Dixon (Syn. P. nervosa D. C. Grew) from Sile (Black Sea coast) in June 2007; Laurencia obtusa var. pyramidata Bory ex J. Agardh (Syn. Laurencia pyramidalis Bory de Saint-Vincent ex Kützing) from Igneada (west part of Turkish Black Sea coast) in June 2007. The sampling sites are shown in the map (Fig. 1). All solvents and chemicals used were Merck products (Darmstadt, Germany).

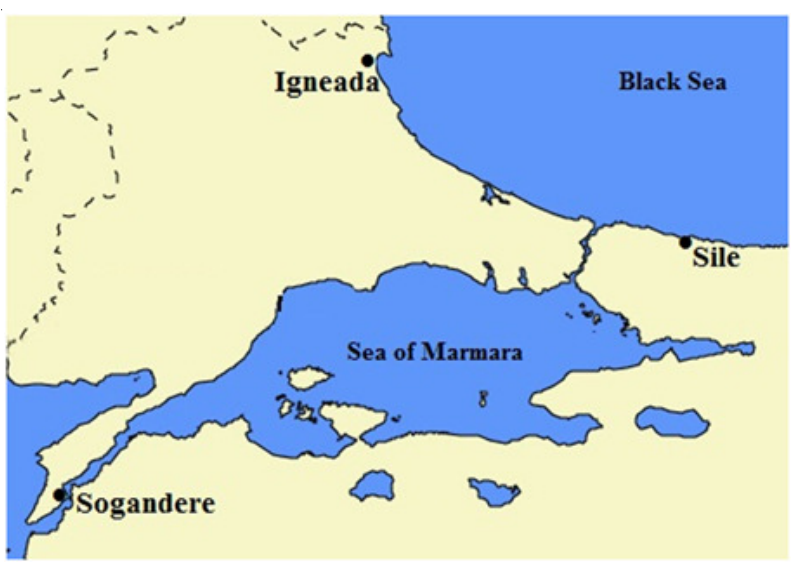

Fig. 1. Sampling sites of the algae 
Extraction: The algae sample is washed with sea water and then distilled water for elimination of sand and other foreign materials. Excess water drained from the algae and then washed with methanol. After drying the algae sample was milled. Powdered algae (60 g) was mixed $40 \mathrm{~g}$ anhydrous sodium sulfate and extracted with dichloromethane in soxhlet apparatus for $8 \mathrm{~h}$. the extract was distilled at $40^{\circ} \mathrm{C}$. The residue was taken with $1 \mathrm{~mL}$ hexane and applied to GC-MS.

GC-MS analysis: HP 6890 capillary GC equipped with a split/splitless injector was used (splitless time $1 \mathrm{~min}$, flow rate $1 \mathrm{~mL} \mathrm{~min}^{-1}, 29.4 \mathrm{psi}$ ) the injector temperature was maintained at $240{ }^{\circ} \mathrm{C}$. The $\mathrm{GC}$ temperature programmed as from $50{ }^{\circ} \mathrm{C}(2 \mathrm{~min})$ to $290{ }^{\circ} \mathrm{C}(15 \mathrm{~min})$ at $5^{\circ} \mathrm{C} \mathrm{min}^{-1}$. The capillary column used is PONO (HP) $60 \mathrm{~m} \times 0.25 \mathrm{~mm} \times 0.25 \mathrm{~mm}$. The
GC was coupled to an HP 5972 Mass Selective Detector. The mass spectrometer was operated under the selective ion monitoring mode and the signal was acquired on the molecule ion of the studied components. (Electron impact at $70 \mathrm{eV}, 2000$ $\mathrm{V}, 1.4$ scans s$^{-1}$, dwell time $40 \mathrm{~ms}$ ). The interference temperature was $290{ }^{\circ} \mathrm{C}$.

The compounds in algal extracts were identified by comparing their spectrum on the peaks on GC with HP memory (Wiley database). Quality of identified compounds on GC-MS is varied $90-99 \%$.

\section{RESULTS AND DISCUSSION}

Exogenic and endogenic compounds found in examined algae are listed in Table-1. The saturated and unsaturated

TABLE-1

OIL COMPONENTS AND BIOGENIC COMPOUNDS DETECTED IN THREE RED ALGAE

\begin{tabular}{|c|c|c|}
\hline Gracilaria bursa-pastoris & Phyllophora crispa & Laurencia obtusa var. pyramidata \\
\hline \multicolumn{3}{|c|}{ Biogenic } \\
\hline Dodenoic acid & Butanoic acid & Eicosane \\
\hline Dodecanoic acid & Tetradecanoic acid & Squalene \\
\hline Dodenoic acid ethyl ester & Hexadecanoic acid & Phytol \\
\hline Hexadecanoic acid & Octadecanoic acid & Hexadecanoic acid \\
\hline Hexadecanoic acid, di octyl ester & & Hexadecanoic acid Palmitic acid ester \\
\hline \multicolumn{3}{|l|}{ Hexadecanoic acid ethyl ester } \\
\hline \multicolumn{3}{|l|}{ Octadecanoic acid } \\
\hline \multicolumn{3}{|l|}{ Pentadecanoic acid } \\
\hline \multicolumn{3}{|l|}{ Tetradecanoic acid } \\
\hline \multicolumn{3}{|l|}{ Tetradecanoic acid ethyl ester } \\
\hline \multicolumn{3}{|c|}{ Exogenic saturated } \\
\hline \multirow[t]{7}{*}{ Heptadecane } & Tridecane & Heptadecane \\
\hline & Tetradecane & Pentadecane \\
\hline & Heptadecane & Tetradecane \\
\hline & Tetracosane & Tetracosane \\
\hline & Heneicosane & Hexacosane \\
\hline & Hexacosane & Pentacosane \\
\hline & Heptacosane & \\
\hline \multicolumn{3}{|c|}{ Exogenic unsaturated } \\
\hline & Heptadecene & $\begin{array}{l}\text { 9,12-Octadecadien-1-ol } \\
\text { Octadecene }\end{array}$ \\
\hline \multicolumn{3}{|c|}{ Cyclic } \\
\hline $\begin{array}{l}\text { 2-Cyclohexen-1-one-2,4,4-trimethyl (3-oxo-1- } \\
\text { butenoyl) }\end{array}$ & $\begin{array}{l}\text { 2,6-Di(tert-butyl)-4-hydroxy-4-methyl-2,5- } \\
\text { cyclohexadiene }\end{array}$ & Cyclohexadecane \\
\hline \multirow{2}{*}{\multicolumn{3}{|c|}{$\begin{array}{l}\text { 2,6-Di(tert-butyl-4-hydroxy-4-methyl-2,5- } \\
\text { cyclohexadiene-1-one } \\
\text { 2-Cyclohexene-1-one,2,4,4-trimethyl-3-(3- } \\
\text { oxo-1-butenyl) }\end{array}$}} \\
\hline & & \\
\hline $\begin{array}{l}\text { cis-11H-benzo[a]fluoren-11-one 6a,11a- } \\
\text { dihydro-9-methoxy-6,6a-dimethyl }\end{array}$ & 3-Nitro-1,2-benzenedicarboxylic acid & 2-(4H)-Benzofuranone \\
\hline $\begin{array}{l}\text { (+,-)-cis-3,4,6,9-Tetrahydro-10-hydroxy-1,3,8- } \\
\text { trimethyl-1H-naphtha-(2,3c)-pyran-6,9-dione }\end{array}$ & Benzene acetic acid & \\
\hline $\begin{array}{l}\text { 1,3,8-Trimethyl-1H-naphtho(2,3c)pyrane-6,9- } \\
\text { dione }\end{array}$ & Benzoic acid & \\
\hline $\begin{array}{l}\text { 9,10-Dihydro-9,9-dimethyl-anthracene } \\
\text { Phenanthrene }\end{array}$ & Butylated hydroxytoluene (BHT) & \\
\hline 2,5-Dimethylphenanthrene & Butylated hydroxybenzaldehyde & \\
\hline Dimethyldibenzothiophene & $1 H$-pyrrole-2,5-dione-3-ethyl-4-methyl & \\
\hline \multicolumn{3}{|l|}{ Nonyl phenol } \\
\hline \multicolumn{3}{|l|}{ Butylated hydroxyl toluene (BHT) } \\
\hline \multicolumn{3}{|c|}{ Chlorinated } \\
\hline Hexachloroethane & 4-Chlorophenol & \\
\hline
\end{tabular}


hydrocarbons (alkenes) found in the examined algae are also as a result of sea pollution. Decane series hydrocarbons in L. papillosa and L. coronopus and cosine series in $L$. coronopus were found ${ }^{22}$. We found these series in L. obtusa var. pyramidata and P. crispa and only heptadecane in G. bursa-pastoris.

Three cyclic alkene derivatives were identified in the same algae. Anthracene, phenanthrene and its derivative and dimethyl benzthiophene which are found in the examined algae, are polyaromatic hydrocarbons and they are very toxic to the environment. Nonyl phenol was found in G. bursa-pastoris in this study and it was also found in seawater ${ }^{29}$, in brown algae Dilophus fasciola ${ }^{30}$. It is also very toxic and a degradation product of non-ionic surfactants nonyl phenol-poly-ethoxylates which is widely used world-wide in detergents, cosmetics, water based paints, inks and textiles.

As indicated in the introduction, many chlorinated aliphatic compounds are endogenous for algae ${ }^{31}$ but hexachloroethane which is found in this work, also known as perchloroethane is used in military purposes. 4-chlorophenol is used for synthesis of dyes and drugs and refining of mineral oils. The origin of these halogenated compounds found in G. bursa-pastoris is unknown.

Butylated hydroxyl toluene is used as a food antioxidant additive for preservative purposes was found in G. bursapastoris and $P$. crispa.

As can be seen in the Table-1, comparison of contamination in collected algae G. bursa-pastoris was found more polluted.

Biogenic compounds phytol, squalene and some fatty acids and their esters were found in examined algae. Of those, phytol is unsaturated alcohol derivated from hydrolysis of chlorophyll. It is precursor of pristane which is used for identification of oil pollution in algae. Phytol was previously found in L. papillosa and L. coronopus ${ }^{22}$. In addition, squalene which is the precursor of cholesterol is found in algae by Rossi et $a{ }^{13}{ }^{13}$. The determined fatty acids were commonly found in $\operatorname{algae}^{22,24-28,30}$

The algae can be used for monitoring the sea pollution but it is difficult to decide whether some hydrocarbons found in algae are biogenic or exogenic.

\section{REFERENCES}

1. K.C. Güven, S. Topcuoglu, D. Kut, N. Esen, N. Erentürk, N. Saygi, E. Cevher, B. Güvener and B. Öztürk, Bot. Mar., 35, 337 (1992).

2. K.C. Guven, N. Saygi and B. Ozturk, Bot. Mar., 36, 175 (1993).
3. K.C. Guven, M. Plevneli, E. Cevher, S. Topcuoglu, N. Kose, M. Bulut and N. Bayulgen, Toxicol. Environ. Chem., 27, 297 (1990).

4. M. George, Nature, 192, 1209 (1961).

5. R.C. Clark and M. Blumer, Limnol. Oceanogr., 12, 79 (1967).

6. S. Erakin and K.C. Guven, Acta Pharm. Sciencia, 50, 167 (2008).

7. O.G. Mironov, T.L. Shchekaturina and I.M. Tsimbal, Mar. Ecol. Prog. Ser., 5, 303 (1981).

8. K.C. Guven, J. Reisch, Z. Kizil, B. Güvener and E. Cevher, Phytochemistry, 29, 3115 (1990).

9. K.C. Guven and B. Coban, Fresenius Environ. Bull., 22, 925 (2013).

10. W.W. Youngblood, M. Blumer, R.L. Guillard and F. Fiore, Mar. Biol., 8, 190 (1971)

11. W.W. Youngblood and M. Blumer, Mar. Biol., 21, 163 (1973).

12. P. Gearing, J.N. Gearing, T.F. Lytle and J.S. Lytle, Geochim. Cosmochim. Acta, 40, 1005 (1976).

13. S. S. Rossi, G.W. Rommel and A.A. Benson, Phytochemistry, 17, 1431 (1978).

14. P. Peckol, S.C. Levings and S.D. Garrity, Mar. Pollut. Bull., 21, 473 (1990).

15. A. Talvari, H. Heinland, H. Kukk and H. Jankovski, Proc. Est. Acad. Sci. Ecol., 2, 50 (1992).

16. U. Kirso and N. Irha, Ecotoxicol. Environ. Saf., 41, 83 (1998).

17. N. Binark, K.C. Guven, T. Gezgin and S. Unlu, Bull. Environ. Contam. Toxicol., 64, 866 (2000).

18. S. DeRosa, Z. Kamenarska, V. Bankova, K. Stefanov, S. Dimitrova, H. Najdenski, I. Tzvetkova and S. Popov, Z. Naturforsch, 56c, 1008 (2001).

19. M.O. Punín Crespo and M.A. Lage Yusty, Ecotoxicol. Environ. Saf., 57, 226 (2004).

20. R.C. Clark Jr and J.S. Finley, Techniques for Analysis of Parafin Hydrocarbons and for Interpretation of Data to Assess Oil Spill Effects in Aquatic Organisms, In: Proceedings of the 1973 Joint Conference on Prevention and Control of Oil Spills, American Petroleum Institute, Washington, D.C., pp. 161 (1979).

21. T. Suzuki, M. Suzuki, A. Furusaki, T. Matsumoto, A. Kato, Y. Imanaka and E. Kurosawa, Tetrahedron Lett., 26, 1329 (1985).

22. Z. Kamenarska, A. Ivanova, R. Stancheva, M. Stoyneva, K. Stefanov, S. Dimitrova-Konaklieva and S. Popov, Bot. Mar., 49, 47 (2006).

23. J. Sun, L.-J. Han, R.-Y. Yang, D.-Y. Shi, Z.-H. Uan and J.-G. Shi, China J. Chinese Mater. Med., 32, 2610 (2007).

24. G.S. El-Baroti, F.K. El-Baz, A. Abd-Elmoein, A.H. Hanaa, A.M.M. Ali and A.E. Ibrahim, Electr. J. Environ. Agric. Food Chem., 10, 2114 (2011).

25. V. Khotimchenko and V.I. Svetashev, Biologia Morya, 5, 45 (1983).

26. L. Chuecas and J.P. Riley, J. Mar. Biol. Assoc. U. K., 46, 153 (1966).

27. S.V. Khotimchenko, V.E. Vaskovsky and V.F. Przhemenetskaya, Phytochem., 30, 207 (1991).

28. Z. Yazici, V. Aysel, E. Oksuz, A. Kose, S. Cumali and K.C. Guven, Toxicol. Environ. Chem., 89, 371 (2007).

29. M.A. Blackburn, S.J. Kirby and M.J. Waldock, Mar. Pollut. Bull., 38, 109 (1999)

30. Z. Kamenarska, S. Dimitrova-Konaklieva, K. Stefanov, H. Najdenski, I. Tzvetkova and S. Popov, Bot. Mar., 45, 502 (2002).

31. O.J. McConnel and W. Fenical, in eds.: H.A. Hoppe, T. Levring and Y. Tanaka, Marine Algae in Pharmaceutical Sciences, Walter DeGruyter, New York, pp. 403 (1979). 